different in their approach to this educational method as the two continents from which they come.

Holton et al. use the traditional approach to problem cases Questions are asked relating to cases presented on one page answers are provided on another with appropriate references. The cases are arranged by micro-organism aetiology and there is a good balance between the most important infections caused by bacteria, viruses and fungi with a short section on parasitic infections. This book is well written, clearly laid out and excellently illustrated.

The approach taken by Barrett is entirely different. The philosophy, as stated, is to stimulate students to educate themselves. Laboratory microbiology, infections and clinical immunology are covered. Each case presentation is followed by some basic questions. Useful information in tables, and lists of broadly appropriate information sources are provided However, there are no answers or commentaries on the cases; these are to be developed by the student. Barrett suggests that the questions provided are merely a start for student's learning. For example, a case of viral pneumonia might ultimately stimulate the student to consider what are the mechanisms of antigenic drift and shift in the influenza virus. The style of this book, and the nature of some cases presented, reflect its American authorship. There are no illustrations.

There are advantages and disadvantages in the different approaches of these books. The availability of answers in Problems in Medical Microbiology does not really encourage students to learn from asking questions themselves in order to solve problems, and in this respect it is not entirely consistent with what educationalists consider 'problem-based learning'. However, this approach does make it easy for students, at all levels, to test their knowledge in a quick, informative and enjoyable way. I expect it will find most use as a revision aid. In contrast, Microbiology and Immunology Casebook is a starting place from which self-education proceeds. To use it effectively, undergraduates need to be highly motivated and carefully guided by an experienced teacher. If used as suggested, learning through use of this book will be very labour-intensive; a medical undergraduate might be expected to complete only a few cases. This book will probably be of more use to postgraduate students and teachers.

M. GILL

\section{Textbook of Diagnostic Microbiology}

Edited by C.R. MAHON and G. MANUSELIA. 1995. ISBN 07216-4028-1. W.B. Saunders Company, Philadelphia. Pp. 1134. $£ 29 \cdot 95$.

This textbook aims to provide a comprehensive introduction to diagnostic microbiology for those entering the field. The 1134 pages are divided into three parts which cover basic principles, the identification of significant isolates and the diagnosis of infections. The principles of laboratory safety and quality control are covered in early chapters together with concepts and procedures in antimicrobial susceptibility testing. How colonial morphology is used for the presumptive identification of organisms is described thoroughly. In addition to these (and other) traditional basic concepts, the first part also covers 'emergent technologies'. These include commercially available rapid identification kits and automated systems, chromatography, DNA probes and the polymerase chain reaction.
The laboratory identification of medically important bacteria, parasites, fungi and viruses is described in part II. As in part I, each of the 16 chapters in part II is laid out clearly with objectives, tables, diagrams and excellent photographs. Part III takes an organ system approach to diagnostic microbiology with chapters covering infections of the respiratory tract, skin, gastrointestinal tract, central nervous system, bloodstream, urinary tract and eye. Chapters are devoted also to sexually transmitted diseases, infections in special patient populations and zoonotic and rickettsial infections. Brief case studies illustrate the course of various infections.

This American book is surprisingly relevant to diagnostic microbiology in the United Kingdom and is well illustrated and easy to read. It covers comprehensively nearly all aspects of diagnostic microbiology (with the possible exception of outbreak investigations and hospital infection control) in an accessible manner and is eminently suitable for those new to the field, especially trainee medical laboratory scientific officers.

J.Z. JORDEN

\section{Bacteria in Biology, Biotechnology and Medicine, 3rd edition}

P. Singleton. 1995. ISBN 0-471-958115. John Wiley and Sons Ltd. Pp. 319. £15.95.

This is a new edition of the textbook published previously as Introduction to Bacteria. The aim of this book is to provide an introduction for university courses in applied biology, microbiology, biotechnology and the health, environmental and food sciences. In contrast to previous editions, a number of areas have been expanded, with particular emphasis on new developments in molecular biology. New to this edition are sections on food hygiene and food poisoning, bioplastics, the greenhouse effect, and the methodology of recombinant DNA technology.

The book is medium-sized (297 pages including an Appendix) and is complemented by many figures, most of which are helpful, although some are a little plain. In general, the text is well-referenced with the majority of references being up-to-date and relevant. The contents include an introduction to bacteria with chapters on the cell, growth and reproduction, differentiation and metabolism. These are followed by some basics of molecular biology and bacteriophages. The next section covers applications; e.g., bacteria in the living world, in medicine and in food. Finally, there are sections on practical bacteriology; e.g., man against bacteria, and the identification and classification of bacteria. Overall, these chapters are well written, although the order in which they are presented is a little odd.

This book is interesting and provides a good introduction to the subject. For its size it is very comprehensive and because of this suffers in being a little sketchy in places. There are very few typographical errors. I would have liked to have seen a greater emphasis on enzyme immunoassays rather than complement-fixation tests, and more on the impilcations of the worrying increase in antibiotic resistance. There is no mention of anaerobic cabinets or electronmicroscopy, and the description of the complement cascade would have benefitted from a diagram. Despite these minor criticisms this is a book that achieves its aim and I would highly recommend it to students for purchase, especially at the current price of under $£ 16$. 